\title{
A FALA DO INTERIOR PAULISTA NO CENÁRIO DA SOCIOLINGUÍSTICA BRASILEIRA: PANORAMA DA CONCORDÂNCIA VERBAL E DA ALTERNÂNCIA PRONOMINAL
}

\author{
Cássio Florêncio RUBIO* \\ Sebastião Carlos Leite GONÇALVES **
}

- RESUMO: Como parte das pesquisas sociolinguísticas desenvolvidas no interior do projeto ALIP (Amostra Linguística do Interior), privilegiamos, neste artigo, a apresentação de resultados gerais decorrentes da investigação de três fenômenos variáveis na fala do interior paulista: (i) a concordância verbal de primeira pessoa do plural; (ii) a concordância verbal de terceira pessoa do plural; (iii) a alternância pronominal entre as formas de codificação da primeira pessoa do discurso do plural nós e a gente. Assumindo os preceitos teórico-metodológicos da Sociolinguística laboviana, mostramos, por meio de comparações interdialetais, como tais fenômenos variáveis se inserem no cenário mais amplo da pesquisa sociolinguística sobre o português brasileiro. Os resultados permitem constatar aproximações e distanciamentos entre a fala do interior paulista e de outras variedades do português brasileiro, o que põe à mostra a importância da descrição de mais essa variedade, ainda pouco conhecida no cenário sociolinguístico brasileiro.

- PALAVRAS-CHAVE: Português paulista. Concordância verbal. Alternância pronominal.

\section{Contextualizando o Projeto ALIP (Amostra Linguística do Interior Paulista)}

Considerando os avanços da pesquisa sociolinguística no Brasil nas últimas décadas, pode-se considerar que os estudos variacionistas sobre as variedades paulistas ainda se encontram na sua infância e, portanto, em dívida com a composição de um retrato sociolinguístico do Português Brasileiro (PB), no que toca ao oferecimento de um espectro mais amplo da fala paulista. Em outras palavras, comparados a trabalhos variacionistas envolvendo outras variedades do PB (citem-se aqui as variedades cariocas, catarinenses, paranaenses, gaúchas, mineiras, pessoenses, dentre outras), podem-se considerar escassos trabalhos nessa mesma linha envolvendo a fala paulista, seja a da capital, seja

* UNILAB - Universidade da Integração Internacional da Lusofonia Afro-Brasileira. Redenção - Ceará - Brasil. 62790-000 - cassiorubio@unilab.edu.br

** UNESP - Universidade Estadual Paulista. Instituto de Biociências, Letras e Ciências Exatas. São José do Rio Preto - São Paulo - Brasil. 15054-000 - scarlos@ibilce.unesp.br 
a do interior. Seria injusto, entretanto, deixar de lembrar aqui que as variedades paulistas já foram objetos de variados projetos de descrição do PB, mas não sob enfoque sociolinguístico. Citem-se, nessa direção, os estudos descritivos desenvolvidos no âmbito do "Projeto Gramática do Português Falado Culto" (CASTILHO, 1990) e os que vêm se desenvolvendo no interior do projeto "Para a história do português paulista" ou "Projeto Caipira", os quais conferem lugar de destaque à investigação das variedades paulistas do PB, assumindo como objetivo principal "[...] investigar emparelhadamente a formação da sociedade paulista e de suas variedades linguísticas, tais como testemunhadas no Estado de São Paulo e em sua capital." (CASTILHO, 2009, p.15).

Em balanço crítico da pesquisa variacionista produzida no estado de São Paulo empregando-se amostras de fala de variedades paulistas, Gonçalves (2012) mostra que só muito recentemente a Sociolinguística vem se firmando no estado, em torno de três projetos de maiores dimensões: o projeto "Amostra Linguística do Interior Paulista" (GONÇALVES, 2007), o projeto "É nóis na fita: sobre a formação de registros e a elaboração de estilos no campo da cultura popular urbana paulista." (BENTES, 2009) e o projeto "SP2010 Construção de uma Amostra da Fala Paulistana" (MENDES, 2011), sediados, respectivamente, na Universidade Estadual Paulista (UNESP/São José do Rio Preto), na Universidade Estadual de Campinas (UNICAMP) e na Universidade de São Paulo (USP), todos subsidiados pela Fundação de Amparo à Pesquisa do Estado de São Paulo (FAPESP). O autor registra ainda o pioneirismo dos trabalhos etnolinguísticos sobre a variedade paulista advindo das contribuições de Amadeu Amaral (1976), em O dialeto caipira, de Ada Rodrigues (1974), sobre o dialeto caipira de Piracicaba, de Mary Careno (1997), sobre a fala de comunidades negras do Vale do Ribeira, dos trabalhos variacionistas de Duarte (1986), sobre a realização de objeto direto anafórico na fala de paulistanos nativos e na linguagem da televisão, e de Ângela Rodrigues (1987), sobre concordância verbal na fala de favelados da capital paulista.

Cientes dessa carência de estudos sociolinguísticos sobre variedades paulistas, sobretudo do interior do estado, instituímos, no ano de 2003, o projeto ALIP, motivados pelos interesses de pesquisas que tinham como principal diretriz o enfoque da língua inserida em seu contexto social. O projeto teve por objetivo primeiro a composição de um banco de dados com amostras do português falado na região de São José de Rio Preto, recurso fundamental para a consolidação de grupos de pesquisa e para a proposição de projetos coletivos de pesquisa. 
Embora inspirados em outros projetos já consolidados (VARSUL, PEUL, VALPB, Gramática \& Discurso), o projeto ALIP não assumiu como prerrogativa para sua proposição interesse por qualquer fenômeno linguístico em particular, mas, sob uma concepção mais ampla e mais aberta, manteve a preocupação de captar o máximo possível do dinamismo linguístico da região noroeste do estado de São Paulo, representada por São José do Rio Preto e seis outras cidades que lhe fazem fronteira: Bady Bassit, Cedral, Guapiaçu, Ipiguá, Mirassol e Onda Verde. Assim, entre os anos de 2004 e 2007, constituímos o banco de dados Iboruna (= rio preto, em Tupi), composto por dois tipos de amostras de fala: a primeira, coletada de acordo com os critérios da Sociolinguística laboviana (LABOV, 1972), constitui a Amostra Censo ou Amostra Comunidade (AC, daqui em diante), e a segunda, coletada secretamente em contextos interacionais livres, sem controle de qualquer variável social (RONCARATI, 1996), constitui a Amostra de Interação (AI, daqui em diante). ${ }^{1}$

Na composição da AC, controlamos as variáveis sociais comprovadamente relevantes nos estudos sociolinguísticos, a saber: sexo/gênero; faixa etária (7 a 15 anos, 16 a 25 anos, 26 a 35 anos, 36 a 55 anos, mais de 55 anos), escolaridade $\left(1^{\circ}\right.$ ciclo do ensino fundamental; $2^{\circ}$ ciclo do ensino fundamental, ensino médio e ensino superior) e renda familiar (até 5 salários mínimos, 6 a 10 salários mínimos, 11 a 25 salários mínimos e mais de 25 salários mínimos). ${ }^{2}$ Do cruzamento das variantes dessas variáveis resultou um total de 152 perfis sociais, dos quais apenas um ainda não foi encontrado na comunidade. A inclusão de área geográfica como mais uma variável de estratificação faria crescer consideravelmente o número de informantes. Assim, para a execução do censo linguístico, os 152 perfis sociais foram distribuídos proporcionalmente por entre as sete cidades da região, considerando a densidade populacional mostrada no quadro 1 a seguir.

O nome IBORUNA (= Rio Preto) tem motivação histórica; é um topônimo de origem tupi-guarani que se pretendeu atribuir a cidade de São José do Rio Preto por ocasião da comemoração do seu cinquentenário. A contundente intervenção do episcopado riopretense não só impediu a mudança como conquistou de maneira definitiva a denominação primitiva, São José do Rio Preto, reduzida a Rio Preto de 1906 a 1944.

2 Cabe aqui uma rápida justificativa acerca da proposição de algumas variantes: no recorte contínuo de faixas etárias, a primeira representa a fase em que os padrões linguísticos estão ainda em fixação; da segunda em diante, a motivação é buscada na pressão social sobre a linguagem do indivíduo, variável de acordo com a inserção no mercado de trabalho (SILVA, 1996); a segmentação das variantes de escolaridade, embora pedagogicamente extinta nos dois primeiros ciclos, preserva diferenças salientes em termos de currículo e metodologia de ensino e representa a divisão escolar em vigor no tempo em que a maioria dos informantes se enquadrava; sobre a variável renda familiar, reconhecendo a dificuldade de divisão de classe social por indicadores diversos, optamos apenas por esse indicador. 


\section{Quadro 1 - Distribuição dos perfis sociais proporcionalmente à densidade populacional das cidades da região.}

\begin{tabular}{|l|c|c|}
\hline \multicolumn{1}{|c|}{ Cidades da Região de São José do Rio Preto } & População & Número de informantes \\
\hline 1. Bady Bassit (12 km ao sul de SJRP) & 11.475 & 04 \\
\hline 2. Cedral (14 km, ao sul de SJRP) & 6.690 & 02 \\
\hline 3. Guapiaçu (16 km, ao leste de SJRP) & 14.049 & 05 \\
\hline 4. Ipiguá (18 km, ao norte de SJRP) & 3.461 & 01 \\
\hline 5. Mirassol $(14 \mathrm{~km}$, a oeste de SJRP) & 48.233 & 16 \\
\hline 6. Onda Verde (25 km, ao norte de SJRP) & 5.407 & 02 \\
\hline 7. São José do Rio Preto & 357.705 & 122 \\
\hline Total da população representada & 447.020 & 152 \\
\hline
\end{tabular}

Fonte: (IBGE, 2000).3

A definição do perfil social desses informantes por cidade seguiu o método da distribuição aleatória (SILVA; SCHERRE, 1996) por área geográfica, que consiste nos seguintes procedimentos: (i) em uma primeira urna, colocamos todos os perfis sociais, identificados pelos números de 1 a 152; (ii) em uma segunda urna, depositamos os nomes de todas as cidades da região; (iii) por meio de escolha ao acaso, retirávamos de cada uma das urnas um perfil social e um nome de cidade, definindo-se assim a origem geográfica do perfil social; (iv) em seguida, devolvíamos apenas para segunda urna o nome da cidade escolhida, até que se atingisse o seu número de informantes; (v) nova escolha combinada era feita, até ser definida a origem geográfica de todos os informantes. Esse procedimento permitiu-nos assegurar a probabilidade de quaisquer dos perfis sociais pertencerem a uma dada cidade.

Definidos os perfis sociais, a constituição de AC, incluindo a localização dos perfis na comunidade, a gravação e a validação da entrevista e sua posterior transcrição ficou sob a responsabilidade de uma equipe técnica composta, na primeira fase do projeto, por 30 integrantes. ${ }^{4}$ Seguindo roteiro previamente elaborado, as entrevistas de AC foram direcionadas para obtenção de cinco tipos de textos de cada informante, com base na metodologia exposta em Votre e Oliveira (1995), a saber: narrativa de experiência pessoal, narrativa recontada, relato de descrição, relato de opinião e relato de procedimento.

Para a constituição da AI, pautada por orientações metodológicas e éticas (RONCARATI, 1996), integrantes da mesma equipe coletaram 11 amostras de interação social livre, cujas descrições são dadas no quadro 2.

\footnotetext{
3 Inclui os Distritos de Talhados e Engenheiro Schmidt

4 Compuseram a equipe um pesquisador coordenador geral, seis pesquisadores colaboradores e 23 auxiliares técnicos.
} 


\section{Quadro 2 - Informações sobre as interações dialógicas de AI.}

\begin{tabular}{|l|l|}
\hline AMOSTRA & CONTEXTO DE INTERAÇÃO-INFORMANTES ENVOLVIDOS \\
\hline AI-001-CAS & $\begin{array}{l}\text { Conversa entre dois homens e cinco mulheres de diferentes idades e escolaridades, em } \\
\text { ambiente familiar. }\end{array}$ \\
\hline AI-002-GIL & $\begin{array}{l}\text { Diálogo entre duas amigas vizinhas, com perfis sociais semelhantes, no portão da casa de } \\
\text { uma delas. }\end{array}$ \\
\hline $\begin{array}{l}\text { AI-003- } \\
\text { ILHA }\end{array}$ & Diálogo entre tia e sobrinha, de diferentes idades e escolaridades, em ambiente familiar. \\
\hline AI-004-OND & $\begin{array}{l}\text { Diálogo entre duas irmãs, de mesma faixa de idade e diferentes escolaridades, em ambiente } \\
\text { familiar. }\end{array}$ \\
\hline AI-005-CAS & Diálogo entre duas estudantes de mesmo perfil social, em ambiente universitário. \\
\hline $\begin{array}{l}\text { AI-006- } \\
\text { MAR }\end{array}$ & Conversa entre quatro mulheres de perfis sociais diferentes, em ambiente familiar. \\
\hline AI-007-FER & $\begin{array}{l}\text { Diálogo entre marido e esposa de mesma faixa etária e de níveis de escolaridade diferentes, } \\
\text { em ambiente familiar. }\end{array}$ \\
\hline $\begin{array}{l}\text { AI-008- } \\
\text { CAM }\end{array}$ & $\begin{array}{l}\text { Conversa entre três estudantes, do sexo masculino e mesmos perfis sociais, em ambiente } \\
\text { universitário. }\end{array}$ \\
\hline AI-009-CAS & $\begin{array}{l}\text { Diálogo entre um advogado e sua cliente, de perfis sociais diferentes, em escritório de } \\
\text { advocacia. }\end{array}$ \\
\hline AI-010-CAS & $\begin{array}{l}\text { Discussão entre dois advogados, de mesmo perfil social, sobre uma peça jurídica, em } \\
\text { escritório de advocacia. }\end{array}$ \\
\hline AI-011-CAS & $\begin{array}{l}\text { Diálogo entre casal de namorados, estudantes universitários de mesma faixa etária, em } \\
\text { ambiente familiar. }\end{array}$ \\
\hline
\end{tabular}

Fonte: GONÇALVES (2005).

$\mathrm{Na}$ fase final do projeto, a preparação definitiva de AC e de AI ficou sob responsabilidade de quatro integrantes da equipe técnica, aos quais coube a tarefa de revisão minuciosa da documentação linguística de cada uma das gravações armazenadas no banco de dados: as transcrições e os respectivos áudios, as fichas sociais, as fichas de validação e os diários de campo. Além desse material, encontram-se disponíveis também no site do projeto ${ }^{5}$ os relatórios de cada fase do projeto, o manual de transcrição e o roteiro de entrevistas. ${ }^{6}$

Feita essa contextualização do projeto ALIP, a continuidade deste artigo estrutura-se em oito seções: na primeira, apresentamos brevemente pesquisas concluídas que se valeram das amostras do banco de dados Iboruna, para, nas seções seguintes, anteriores à conclusão e centrais deste artigo, oferecermos um panorama da concordância verbal (CV, daqui em diante) e da alternância pronominal (AP, daqui em diante) na fala do interior paulista, estabelecendo, a partir dos resultados alcançados para os fenômenos variáveis aí envolvidos, comparações interdialetais.

5 Disponível em: <www.iboruna.ibilce.unesp.br>.

6 Para maiores informações sobre questões teóricas e metodológicas do projeto ALIP, remetemos o leitor a Gonçalves (2008). 


\section{Projeto ALIP: esboço de um retrato sociolinguístico da região noroeste do estado de SP}

Próximo de completar sua primeira década de existência, o projeto ALIP e o banco de dados Iboruna já propiciaram importantes trabalhos descritivos da fala do interior paulista, tanto da perspectiva sociolinguística quanto de uma perspectiva funcionalista, não variacionista, de modo que um retrato sociolinguístico da região já começa a se esboçar.

Da perspectiva variacionista, os fenômenos já investigados contemplam os níveis fonético-fonológico e morfossintático. Integrados ao "Projeto de descrição sócio-histórica das vogais do português brasileiro" (PROBRAVO), que tem por objetivo descrever as realizações fonéticas de vogais nos dialetos de Sul a Norte do Brasil, trabalhos variacionistas envolvendo o dialeto paulista vêm se consolidando no estado de São Paulo, sob a coordenação da Profa. L. E. Tenani, da Unesp de São José do Rio Preto, a exemplo da descrição de outros dialetos que têm lugar no interior do projeto nacional, a saber: dialetos mineiros, dialetos do Sul, dialeto da Paraíba, dialeto mato-grossense, dialeto do Pará, dialeto de Rondônia, dialeto capixaba, dialeto baiano e dialeto carioca. ${ }^{7}$ Mais especificamente, com base nas amostras de fala do banco de dados Iboruna, as contribuições com PROBRAVO incluem resultados para os seguintes fenômenos variáveis: (i) alçamento vocálico em contextos de postônica medial de nomes, como em c[o]zinha $\sim$ c[u]zinha e t[e],soura t[i]/Soura (SILVEIRA, 2008), e de verbos, como em d[e]via d[i]via e p[o]dia p[u]dia (CARMO, 2009); (ii) alçamento e síncope de postônicas mediais, como em pês.s[e].go pês.s[i].go pês.go e a.bó.[bo].ra a.bó.[bu].ra a.bó. [bra] (RAMOS, 2009).

Não diretamente ligados ao PROBRAVO, outros fenômenos fonéticos também já dispõem de resultados interessantes. Um exemplo é o trabalho de Ferreira (2010) sobre a redução de gerúndio, como em canta[ndo] canta[no], traço marcante da fala paulista interiorana, que alcança percentuais elevadíssimos de aplicação da alternante reduzida (72\%), frente a outras variedades.

Resultados para fenômenos variáveis de ordem morfossintática incluem a expressão de futuro sintético $x$ futuro analítico (FONSECA, 2010); a expressão de aspecto cursivo por meio de perífrases verbais, como em andar $x$ continuar $x$ ficar $x$ viver + gerúndio (FERNANDES, 2010); a realização de preposições com $x$ sem contração, como em com a cu'a c'a, para pra pa etc. (MARCATO,

O PROBRAVO, composto por pesquisadores de 17 universidades brasileiras, foi criado em 2005 e, sediado na Universidade Federal de Minas Gerais, é atualmente coordenado pelos Profs. S. Lee e M. A. Oliveira. De modo articulado, vem procurando responder às seguintes questões: (i) como são realizadas foneticamente as vogais no PB? (ii) como se explica ou o que motiva a diversidade de realizações fonéticas? (iii) como os falantes do PB se entendem, apesar das diversidades da qualidade vocálica? (iv) é possível explicar essa diversidade gramaticalmente? (Informações disponíveis em: <http://relin.letras.ufmg.br/probravo>. Acesso em: 22 fev. 2012). 
2011); a expressão de cópula em orações matrizes predicativas, como em é claro que claro que (FORTILLI, 2011); a alternância indicativo/subjuntivo em orações complexas (SANTOS, 2005); a marcação de plural em sintagmas nominais (FIAMENGUI, 2011) e em contextos de predicativo (SALOMÃO, 2010); a concordância verbal de 3PP (RUBIO, 2008) e padrões de concordância verbal e de alternância pronominal (RUBIO, 2012).

O banco de dados Iboruna tem servido ainda ao desenvolvimento de inúmeras pesquisas de descrição do português falado sob a perspectiva funcionalista, não variacionista. Dentre as várias pesquisas já concluídas, citemos: o uso de marcadores discursivos (GUERRA, 2007; PENHAVEL, 2010), a gramaticalização de juntivos (FELÍCIO, 2008; GALBIATI, 2010; SOUZA, 2009; RENCK, 2011), a gramaticalização e a combinação de orações (GONÇALVES, 2011; SANTANA, 2010), a expressão de evidencialidade (VENDRAME, 2010) e o uso de predicações não verbais (FORTILLI, 2007).

Rotulado, de modo mais amplo, de sociofuncionalista, outro conjunto de trabalhos vem sendo desenvolvido, combinando-se as perspectivas da variação e da gramaticalização. Incluem-se nessa vertente a investigação de preposições com verbos de movimento (WIEDEMER, 2011), a alternância nós $x$ a gente, o alçamento de constituintes (GONÇALVES, 2012) e as predicações reduzidas encaixadas em predicados avaliativos (LIMA, 2012).

Dentre os inúmeros fenômenos variáveis comprovadamente presentes no PB do interior paulista, nossa motivação para o enfoque, neste artigo, apenas de fenômenos relacionados à CV e à AP, deve-se ao fato de esses constituírem fenômenos amplamente difundidos em grande número de regiões do território brasileiro, o que se comprova pelos inúmeros estudos já realizados para as também inúmeras variedades do $\mathrm{PB}$, o que permite a realização de uma análise sociolinguística comparativa e a comprovação de possíveis padrões de variação nessas variedades de língua portuguesa existentes no Brasil. É do que passamos a tratar nas seções seguintes.

\section{Panorama da concordância verbal e da alternância pronominal na fala do interior paulista}

Segundo Weinreich, Labov e Herzog (1968), a mudança linguística necessariamente deve ser concebida como encaixada no sistema linguístico e na matriz social, sem que isso implique, no entanto, concebê-la como um movimento de um sistema inteiro para outro completamente diferente. Em outras palavras, o que ocorre, num processo de mudança, é a alteração gradual de um conjunto limitado de variáveis num sistema. O controle dessa variação pode ser apreendido a partir da competência linguística dos membros da 
comunidade de fala. Da mesma forma, no desenvolvimento da mudança linguística, a estrutura social pode pesar de forma diferente sobre o sistema linguístico abstrato. A questão do encaixamento, portanto, lidará com o entrelaçamento das mudanças com outras que poderão afetar tanto a estrutura linguística quanto a estrutura social.

Especificamente, no fenômeno variável da concordância verbal (CV, daqui em diante), a redução no paradigma da conjugação verbal acarreta alterações em outro subsistema da língua, como, por exemplo, na estrutura oracional, levando a um maior preenchimento da posição de sujeito, nos casos em que há o emprego de verbo no singular para sujeito plural, semelhantemente ao que ocorre em outras línguas. Contribui também para a redução do paradigma verbal a implementação de outras formas pronominais, como as formas você/ vocês, para a segunda pessoa do singular/plural (2PS/2PP, daqui em diante), e a gente, para a primeira pessoa do plural (1PP, daqui em diante), que, com maior frequência, se vinculam às formas verbais de terceira pessoa.

A alternância pronominal (AP, daqui em diante) de 1PP talvez seja, dos fenômenos variáveis no PB, o que mais apresente sinais de encaixamento na matriz social, visto que se mostra presente em todos os segmentos sociais de inúmeras variedades, o que significa um grande passo no processo de sua implementação ou aceitação.

Com vistas ao oferecimento de um panorama dos fenômenos de CV e de AP, apresentamos, a seguir, um quadro resumo de realizações pronominais e respectivos padrões de CV verificados em diferentes variedades do $\mathrm{PB}$, com destaque para a variedade falada no interior paulista, os quais podem ser contrastados com os padrões normativos da língua portuguesa. ${ }^{8}$

8 Para fenômenos variáveis envolvendo 1PP do discurso e 3PP, procedemos à análise quantitativa e qualitativa e, para a primeira pessoa do singular (1PS, daqui em diante), 2PS e 2PP do discurso e terceira pessoa do singular (3PS, daqui em diante), procedemos à análise apenas qualitativa. 


\section{Quadro 3 - Realizações pronominais e formas correlatas e padrões de conjugação verbal em variedades do PB.}

\begin{tabular}{|c|c|c|c|c|c|c|}
\hline \multirow{2}{*}{$\mid \begin{array}{r}\text { Yariedad } \\
\text { es } \\
\text { Pessoa }\end{array}$} & \multicolumn{2}{|c|}{ PADRÃO } & \multicolumn{2}{|c|}{$\begin{array}{l}\text { ESTUDOS DO } \\
\text { PORTUGUÊS } \\
\text { BRASILEIRO }^{8}\end{array}$} & \multicolumn{2}{|c|}{$\begin{array}{c}\text { PORTUGUÊS } \\
\text { BRASILEIRO DO } \\
\text { INTERIOR PAULISTA }{ }^{9}\end{array}$} \\
\hline & $\begin{array}{l}\text { Pronome e } \\
\text { correlatos }\end{array}$ & $\begin{array}{l}\text { Conjugaçã } \\
\text { o/ } \\
\text { Exemplo }\end{array}$ & $\begin{array}{l}\text { Pronome } \\
\text { e } \\
\text { Correlat } \\
\text { os }\end{array}$ & $\begin{array}{c}\text { Conjugação/ } \\
\text { Exemplo }\end{array}$ & $\begin{array}{l}\text { Pronome e } \\
\text { Correlatos }\end{array}$ & $\begin{array}{c}\text { Conjugação } \\
/ / \\
\text { Exemplo }\end{array}$ \\
\hline 1PS ${ }^{10}$ & $\mathrm{Eu}$ & $\begin{array}{l}1 \mathrm{PS} / \\
\text { canto }\end{array}$ & $\mathrm{Eu}$ & $\begin{array}{l}1 \mathrm{PS} \times(3 \mathrm{PS}) / \\
\text { canto } x(\text { canta })\end{array}$ & $\mathrm{Eu}$ & $\begin{array}{l}1 \mathrm{PS} / \\
\text { canto }\end{array}$ \\
\hline \multirow[t]{2}{*}{ 2PS } & \multirow[t]{2}{*}{$\mathrm{Tu}$} & \multirow[t]{2}{*}{$\begin{array}{l}\text { 2PS / } \\
\text { cantas }\end{array}$} & $\mathrm{Tu}$ & $\begin{array}{l}2 \mathrm{PS} \times 3 \mathrm{PS} / \\
\text { cantas } x \text { canta }\end{array}$ & \multirow[t]{2}{*}{ Você } & \multirow[t]{2}{*}{$\begin{array}{l}\text { 3PS / } \\
\text { canta }\end{array}$} \\
\hline & & & Você & 3PS / canta & & \\
\hline \multirow[t]{2}{*}{$3 P S^{11}$} & $\begin{array}{l}\text { Ele/a e } \\
\text { correlatos }\end{array}$ & $\begin{array}{l}3 \mathrm{PS}, 3 \mathrm{PP} / \\
\text { canta } x \\
\text { (cantam) }\end{array}$ & $\begin{array}{l}\text { Ele/a e } \\
\text { correlatos }\end{array}$ & $\begin{array}{l}\text { 3PS } \times(3 \mathrm{PP}) / \\
\text { canta } x(\text { cantam })\end{array}$ & $\begin{array}{l}\text { Ele/a } \\
\text { correlatos }\end{array}$ & $\begin{array}{l}3 \mathrm{PS} \times(3 \mathrm{PP}) \\
/ \\
\text { canta } x \\
(\text { cantam) }\end{array}$ \\
\hline & $\begin{array}{l}\text { Coletivo } \\
\text { (povo) }\end{array}$ & $\begin{array}{ll}\text { PPS } \times & 3 \mathrm{PP} \\
1 & \\
\text { canta } & x \\
\text { cantam } & \\
\end{array}$ & $\begin{array}{l}\text { Coletivo } \\
\text { (povo) }\end{array}$ & $\begin{array}{l}3 \mathrm{PS} \times 3 \mathrm{PP} / \\
\text { canta } x \text { cantam }\end{array}$ & $\begin{array}{l}\text { Coletivo } \\
\text { (povo) }\end{array}$ & $\begin{array}{l}3 \mathrm{PS} \times 3 \mathrm{PP} / \\
\text { canta } \quad x \\
\text { cantam }\end{array}$ \\
\hline \multirow[t]{2}{*}{ 1PP } & \multirow[t]{2}{*}{$\begin{array}{l}\text { Nós e } \\
\text { correlatos }\end{array}$} & \multirow[t]{2}{*}{$\begin{array}{l}1 \mathrm{PP} / \\
\text { cantamos }\end{array}$} & $\begin{array}{l}\text { Nós } \mathrm{e} \\
\text { correlatos }\end{array}$ & $\begin{array}{l}1 \mathrm{PP} \times 3 \mathrm{PS} / \\
\text { cantamos } x \text { canta }\end{array}$ & $\begin{array}{ll}\text { Nós } & \mathrm{e} \\
\text { correlatos }\end{array}$ & $\begin{array}{l}1 \mathrm{PP} \times 3 \mathrm{PS} / \\
\text { cantamos } \quad x \\
\text { canta }\end{array}$ \\
\hline & & & A gente & $\begin{array}{l}3 \mathrm{PS} \times 1 \mathrm{PP} \times(3 \mathrm{PP}) \\
/ \\
\text { canta } x \text { cantamos } \\
x(\text { cantam })\end{array}$ & A gente & $\begin{array}{l}3 \mathrm{PS} \times 1 \mathrm{PP} / \\
\text { canta } x \\
\text { (cantamos) }\end{array}$ \\
\hline 2PP & Vós & $\begin{array}{l}2 \mathrm{PP} / \\
\text { cantais }\end{array}$ & Vocês & $\begin{array}{l}3 \mathrm{PP} \times 3 \mathrm{PS} / \\
\text { cantam } x \text { canta }\end{array}$ & Vocês & $\begin{array}{l}\text { 3PP } \mathrm{P} \text { 3PS / } \\
\text { cantam } \\
\text { canta }\end{array}$ \\
\hline 3PP & $\begin{array}{l}\text { Ele/as e } \\
\text { correlatos }\end{array}$ & $\begin{array}{l}3 \mathrm{PP} / \\
\text { cantam }\end{array}$ & $\begin{array}{l}\text { Ele/as e } \\
\text { correlatos }\end{array}$ & $\begin{array}{l}3 \mathrm{PP} \times 3 \mathrm{PS} / \\
\text { cantam } x \text { canta }\end{array}$ & $\begin{array}{l}\text { Ele/as } \mathrm{e} \\
\text { correlatos }\end{array}$ & $\begin{array}{l}\text { 3PP x 3PS / } \\
\text { cantam } x \\
\text { canta }\end{array}$ \\
\hline
\end{tabular}

Fonte: RUBIO (2012). ${ }^{9} 101112$

9 Dados relativos ao PB tomam por base os resultados dos trabalhos de Lucchesi, Baxter e Silva (2009) e Lopes e Naro (2011), para a 1PS; Loregian (1996), Paredes Silva (1996), Hausen (2000), Orlandi (2004), Amaral (2003) e Modesto (2006), para a 2PS; Scherre e Naro (1998a), Mattos (2003) e Rubio (2012), para a 3PS; Bortoni-Ricardo (1985), Rodrigues (1987), Omena (1986, 2003), Lopes (1999), Naro, Görski e Fernandes (1999), Zilles, Maya e Silva (2000), Zilles (2005, 2007), Vianna (2006), Coelho (2006), Lucchesi Baxter e Silva (2009), para a 1PP; Bechara (2002), Neves (2000) e Perini (2010), para a 2PP; Lemle e Naro (1977), Nina (1980), Nicolau (1984), Rodrigues (1987), Graciosa (1991), Naro e Scherre (1999, 2000a, 2000b, 2003 e 2007), Scherre e Naro (1993, 1997, 1998a, 1998b, 1999, 2001, 2006), Monguilhott e Coelho (2002), Silva e Lucchesi (2006), Gameiro (2005), Monte (2007), para 3PP.

10 Dados relativos ao PB do interior paulista tomam por base os trabalhos de Rubio $(2008,2012)$.

11 As formas entre parênteses constituem fenômenos pouco recorrentes, mas já atestados.

12 A tradição gramatical admite variação na CV somente nos casos específicos de sujeito partitivo (núcleo singular com elementos plurais adjacentes) ou de sentido coletivo. 
Como se observa no quadro acima, no tocante à expressão pronominal, o PB, de forma geral, dispõe de oito formas, duas das quais com alternância: 2PS (tu X você) e 1PP (nós x a gente). Essa situação se reduz, se consideradas variedades específicas como a do interior paulista, que apresenta sete formas pronominais, com alternância em apenas uma delas (nós $x$ a gente).

Quando se consideram os diferentes padrões de CV, à exceção da 2PS, expressa pelo pronome você, que apresenta padrão único de CV com 3PS (regra categórica, portanto), a regra de CV é variável para as formas pronominais, em maior ou menor grau, prevalecendo, nos diferentes padrões, para cada uma delas, a 3PS. Na variedade do interior paulista, também escapa a essa constatação a CV com 1PS.

A investigação dos fenômenos variáveis envolvendo tanto o quadro pronominal quanto os padrões de CV no PB demandaria, certamente, trabalho de maior fôlego, motivo pelo qual nos restringimos, neste artigo, ao enfoque dos fenômenos variáveis comuns à amostra do interior paulista (em destaque no quadro apresentado). Fundamentados na literatura pertinente, para a CV variável de 3PS e 2PP, apresentamos apenas ocorrências exemplificativas que comprovam tratar-se de fenômenos variáveis também na fala do interior paulista, e, para AP e CV de 1PP do discurso e CV de 3PP, apresentamos análises qualitativas e quantitativas, focalizando os resultados gerais e contrastando-os com os de outras variedades do $\mathrm{PB}$.

\section{Variação na concordância verbal de terceira pessoa do singular (3PS)}

Considerando a 3PS, é possível verificar a ocorrência de variação entre o uso de formas verbais de 3PS e de 3PP nos chamados casos de concordância semântica, nos quais o núcleo do sujeito tem significado coletivo (povo, multidão, pessoal, grupo, turma, por exemplo).

As gramáticas normativas aludem ao fenômeno variável como uma "concordância ideológica." Cunha e Cintra (1984, p.602) afirma que a silepse, figura de sintaxe de efeito expressivo, apresenta coesão significativa, ocasionada pelo contexto geral e pela situação. A concordância, nesse caso, faz-se com o sentido e não com a forma gramatical das palavras. No caso da silepse de número, um substantivo que se encontra no singular pode ser semanticamente considerado como plural, por ser coletivo (o povo votaram...).

Segundo Scherre e Naro (1993), a variação ocorre também nas estruturas complexas que se apresentam normalmente em construções cujo núcleo do sujeito é singular (seja ele de natureza quantitativa ou não) seguido de um SPrep de núcleo plural, que ocasiona uma leitura quantitativa, coletiva ou partitiva. 
No PB do interior paulista, o fenômeno variável também é observado, conforme apresentamos a seguir, nas ocorrências exemplificativas recolhidas do banco de dados Iboruna. ${ }^{13}$

(1.a) é quase como na saúde né? Existe meia dúzia de privilegiados né? que GAnham MUIto...[Doc.: hum::.] e.: e também existe a maioria que ganha muito $\mathrm{po}(\mathrm{u}) \mathrm{co}$

[BDI-AC-138-305]

(1.b) uma parte dos impostos deviam... ficá(r) pra assim... tê(r) um/ a gente ter $\mathrm{o}$ atendimento

[BDI-AC-138-277]

(1.c) a maioria das famílias num aceita e eu acabo tendo PEna dessas pessoas porque eles são muito simples...

[BDI-AC-152-540]

Nas ocorrências, verifica-se o uso de formas verbais em 3PS e 3PP, junto de expressões complexas de núcleo singular, invariavelmente, na 3PS, que possuem um SPrep de núcleo plural ((1.a) a (1.c)). Embora, em termos frequenciais, essas ocorrências não sejam suficientes para investigação sociolinguística, elas apontam para existência de variação de CV de 3PS também na variedade brasileira do interior paulista.

\section{Variação na concordância verbal com segunda pessoa do plural (2PP)}

A forma pronominal vocês (e suas variantes, ocês, cês, cêis), no PB, é utilizada categoricamente para a representação da 2PP do discurso, em lugar da forma padrão, vós. Segundo Perini (2010), alguns itens tradicionalmente analisados como pronomes pessoais não ocorrem no PB, como a forma vós, que é somente usada na língua escrita em determinados contextos religiosos. No PB, a CV com 2PP do discurso é variável, com emprego de verbos em 3PS e em 3PP junto do pronome vocês, fenômeno também presente na variedade do interior paulista, como se observa nas ocorrências extraídas das amostras de interação do Iboruna. ${ }^{14}$

13 Ao final de cada ocorrência, apresentamos, entre colchetes, respectivamente: a origem das amostras, BDI (banco de dados Iboruna), o tipo de amostra, AC ou AI (amostra censo ou amostra de interação), o número de identificação do perfil social do informante e a linha da ocorrência.

14 Os tipos textuais que constituem a amostra censo restringem a ocorrência de formas de 2PP, encontradas apenas nas amostras de interação. Embora, nesse tipo de amostra, ocorram 2PS e 2PP, as ocorrências não são suficientes para estudo quantitativo. Nota-se também fenômeno de ordem fonético-fonológica no uso do pronome, com a alternância entre as formas vocês e cê(i)S. 
(2.a) Cês assiste também esse programa?... nós assiste TOdo dia... bom eu quando tô em casa

[BDI-AI-002-30]

(2.b) - "mas cês num tá ensinan(d)o direi::to"- ... ela ainda falava -"eu quero aprende mais"-

[BDI-AI-004-65]

(2.c) a gente vê que cês dão muito valor no estudo... cês é:..... cês a::cha importan::te estudá::(r)

[BDI-AI-004-45

(2.d) então mas vocês nunca/... vocês nunca foram no fórum pra resolvê(r) isso?

[BDI-AI-009-78]

(2.e) cê sa/ lembra onde tem um xerox? ... ali pela rodoviá::ria tal?... cês num entraram por ali?

[BDI-AI-008-220]

Não obstante a referência, nesses casos, seja à 2PP, o comportamento em relação à CV é semelhante ao verificado junto dos pronomes de 3PP, eles e elas. As observações sobre o fenômeno de 2PP aqui apresentadas, embora superficiais, apontam, ao menos, para a necessidade de uma investigação mais acurada desses contextos passíveis de variação.

\section{Alternância pronominal no uso da primeira pessoa do plural (1PP) do discurso}

Em relação à 1PP do discurso, observam-se, no $\mathrm{PB}$, fenômenos variáveis de AP e de CV. Para o estudo da AP de 1PP no PB do interior paulista, foi analisado um total de 2.173 ocorrências das formas pronominais nós e a gente explícitas (plenas) e não explícitas (desinenciais ou nulas), com 1.603 casos da forma pronominal a gente (1.413 ocorrências do pronome explícito e 190 do pronome não explícito) e 570 da forma pronominal nós (477 casos de nós explícito e 93 casos de nós não explícito). Seguem, na tabela 1, os percentuais de distribuição das ocorrências. 
Tabela 1 - Alternância pronominal de primeira pessoa do plural

(nós x a gente) no português brasileiro do interior paulista.

\begin{tabular}{cccccc}
\hline VARIEDADE & \multicolumn{2}{c}{ NÓS } & \multicolumn{2}{c}{ A GENTE } & TOTAL \\
\hline PB - IBORUNA & \multicolumn{2}{c}{$26,2 \%(570)$} & \multicolumn{2}{c}{$73,8 \%(1.603)$} & \\
SUJEITO & explícito & não & explícito & não & $100 \%$ \\
PRONOMINAL & $83,7 \%$ & explícito & $88,1 \%$ & explícito & \multirow{2}{*}{$(2.173)$} \\
& $(477)$ & $16,3 \%(93)$ & $(1.413)$ & $11,9 \%(190)$ & \\
\hline
\end{tabular}

Fonte: RUBIO (2012).

Para a fala do interior paulista, os resultados apontam que a forma inovadora a gente (como em (3.a)) predomina sobre a forma pronominal conservadora nós (como em (3.b)), com percentual de uso de 73,8\%. Para ambas as formas de codificação do 1PP, sujeitos explícitos (identificados por (i) nas ocorrências (3.a) e (3.b)) prevalecem acentuadamente sobre os não explícitos (identificados por (ii) nas ocorrências).

(3.a) lá em casa (i) a gente... num tinha diNHE(i)ro... (ii) num tinha RO(u)pa [BDI-074-505]

(3.b) eu trabalhava com trabalho de roça... lá (i) nós mexíamos com MUda (ii) preparávamos mudas de café...

[BDI-114-60]

Apresentamos o quadro de variáveis consideradas na investigação da AP de 1 PP e respectiva ordem de seleção apontada pelo programa estatístico GOLDVARB.

\section{Quadro 4 - Ordem de seleção das variáveis consideradas para o fenômeno de alternância pronominal de primeira pessoa do plural no português brasileiro do interior paulista.}

\begin{tabular}{|c|c|c|}
\hline \multicolumn{2}{|c|}{$\begin{array}{ll}\text { Variáveis } & \text { Fenômeno } \\
\end{array}$} & $\begin{array}{c}\text { Nós x A gente } \\
\text { PB do interior paulista - IBORUNA }\end{array}$ \\
\hline \multirow{5}{*}{ 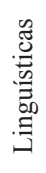 } & Paralelismo linguístico discursivo & $1^{\circ}$ \\
\hline & Saliência fônica verbal & $2^{\circ}$ \\
\hline & Grau de determinação do sujeito & $5^{\circ}$ \\
\hline & Tempo e modo verbal & $6^{\circ}$ \\
\hline & Preenchimento do sujeito & não selecionada \\
\hline \multirow{3}{*}{$\begin{array}{l}\frac{n}{\pi} \\
\frac{\pi}{0} \\
\mathscr{D} \\
\mathscr{n}\end{array}$} & Escolaridade & $4^{\circ}$ \\
\hline & Faixa etária & $3^{\circ}$ \\
\hline & Gênero & não selecionada \\
\hline
\end{tabular}

Fonte: RUBIO (2012). 
É possível observar, no quadro, que, dentre as variáveis linguísticas, paralelismo linguístico discursivo foi selecionado o fator mais relevante no fenômeno. Saliência fônica verbal, grau de determinação do sujeito e tempo e modo verbal foram selecionados em $2^{\circ}$, em $5^{\circ}$ e em $6^{\circ}$ lugares, respectivamente. O grupo de fatores preenchimento do sujeito, que controla os contextos de sujeito explícito e de sujeito não explícito, foi o único não selecionado pelo programa GOLDVARB, o que revela que a variável possui pouco peso no processo de AP na amostra considerada. Relativamente às variáveis sociais, sobressaem-se faixa etária e escolaridade, que foram selecionadas como relevantes em $3^{\circ}$ e $4^{\circ}$ lugares. Gênero foi considerado estatisticamente não relevante. A partir desses resultados, um primeiro julgamento é o de que, no PB do interior paulista, é forte a atuação de variáveis tanto linguísticas quanto sociais na AP de 1PP.

Efetuamos a comparação dos resultados gerais obtidos em nosso estudo com resultados evidenciados em outras variedades do Estado de São Paulo e em variedades de outros estados brasileiros, a fim de verificar as possíveis semelhanças e discrepâncias de percentuais da AP em diferentes variedades da língua portuguesa. ${ }^{15}$

\section{Gráfico 1 - Alternância pronominal de primeira pessoa do plural nós e a gente em diferentes variedades do português brasileiro.}

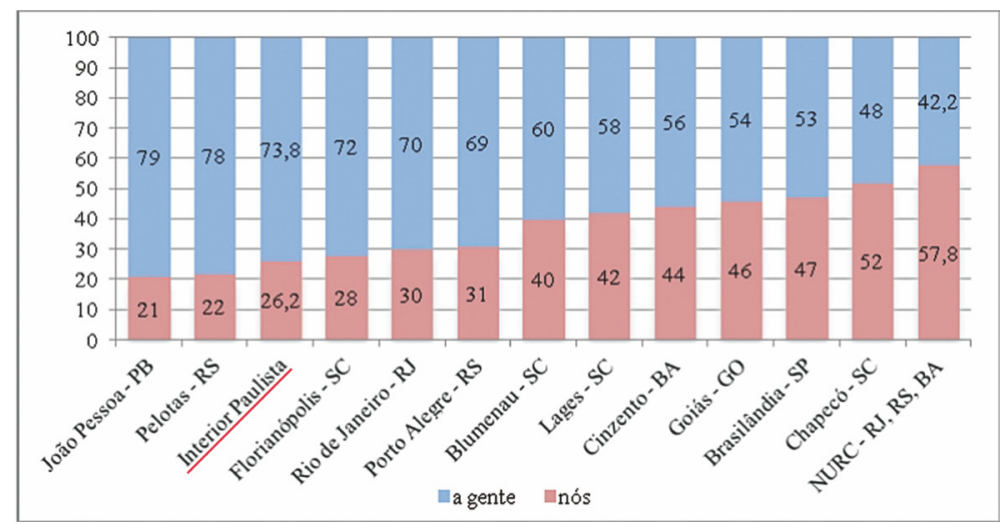

Fonte: Elaboração própria. ${ }^{16}$

15 Lembremos que não é nosso intuito contemplar todos os estudos já realizados sobre AP de 1PP, mas oferecer somente um panorama do fenômeno, na consideração de fatores de ordem diatópica e diastrática.

16 Características sociais das amostras: João Pessoa-PB (FERNANDES, 1999): escolaridade de nula a superior; faixa etária de 15 a 25, de 26 a 49 e de mais de 50 anos; e gêneros masculino e feminino; Pelotas-RS-Projeto VARX (BORGES, 2004): escolaridade fundamental, média, superior; faixa etária de 16 a 25, de 26 a 37 , de 38 a 49 , de 50 a 64 e de mais 65; e gêneros masculino e feminino; Interior Paulista-Iboruna (RUBIO, 2012): escolaridade fundamental, média, superior; faixa etária de 16 a 25, de 26 a 35, de 36 a 55 e de mais de 55; e gêneros feminino e masculino; Florianópolis-SC-Projeto VARSUL (SEARA, 2000): escolaridade primária, ginasial e secundária; faixa etária de 15 a 24, de 25 a 50 e de mais de 50; e gêneros feminino e masculino; Rio de Janeiro-RJ (OMENA; BRAGA, 1996): escolaridade fundamental e média; faixa etária de 7 a 14, de 15 a 25, de 26 a 49 e de 50 a 71 
Sem perder de vista a diferença na estratificação social dos corpora em que cada investigação se baseia, os resultados do gráfico acima permitem evidenciar que as variedades do PB apresentam diferenças no uso das formas pronominais nós e a gente, com uma discrepância, se comparadas as variedades dos extremos do gráfico, de quase 37 pontos percentuais.

Em variedades de diferentes regiões e estados brasileiros, como a de João Pessoa (PB), a de Pelotas (RS), a do interior paulista, a de Florianópolis (SC), a do Rio de Janeiro (RJ) e a de Porto Alegre (RS), nota-se, pelos percentuais de emprego da forma a gente $(79 \%, 78 \%, 69 \%$ e 73,8\%, 72\%, 70\% e 69\%, respectivamente), o predomínio acentuado da forma inovadora sobre a forma conservadora, o que, contudo, não se estende a todas as variedades do território brasileiro. É possível verificar certo equilíbrio entre as formas alternantes, em determinadas comunidades, como a de Brasilândia, na periferia de São Paulo, e a do estado de Goiás, que apresentaram, respectivamente, 53\% e 54\% de emprego da forma inovadora, a despeito de apresentarem estratificação social diferentes (confira nota 15).

O ligeiro predomínio do pronome nós foi atestado recentemente em Chapecó (SC), com 52\% de emprego dessa forma, em oposição aos 48\% de emprego da forma a gente, o que aproxima essa variedade popular à do PB culto falado nas cidades do Rio de Janeiro, Salvador e Porto Alegre, consideradas conjuntamente por Lopes (1999), que constatou uma frequência de 57,8\% de uso de nós contra $42,2 \%$ de uso de a gente.

Essa constatação, aliada à observação de outros estudos do PB, confirma que a escolaridade não é fator que exerce forte influência no fenômeno variável da AP, já que, apesar de a maioria dos trabalhos considerar informantes de todas as faixas escolares (desde escolaridade nula até superior), constatamse aproximações e distanciamentos entre as diferentes variedades do PB. Observam-se, por exemplo, aproximações entre a variedade de Cinzento-BA (44\% de emprego de nós), com informantes de escolarização nula ou baixa; a de LagesSC (42\% de uso de nós), com informantes de escolaridade primária, ginasial e

anos; e gêneros masculino e feminino; Porto Alegre-RS (ZILLES; MAYA; SILVA, 2000): escolaridade de baixa até superior; faixa etária de 25 a 49 e de mais de 50 anos; e gêneros feminino e masculino; Blumenau-SC (TAMANINE, 2002): escolaridade primária, ginasial e secundária; faixa etária de até 45 anos e de mais de 50; e gêneros masculino e feminino; Lages-SC (TAMANINE, 2002): escolaridade primária, ginasial e secundária; faixa etária de até 45 anos e de mais de 50 anos; e gêneros masculino e feminino; Cinzento-BA (ANTONINO; BANDEIRA, 2011): escolaridade baixa ou nula; faixa etária de 20 a 40, de 41 a 60, de 61 a 80 e de mais de 80 anos; e gêneros feminino e masculino; Goiás-GO (MATTOS, 2010): escolaridade média e superior; faixa etária de menos de 21, de 21 a 40 e acima de 41; e gêneros masculino e feminino; Brasilândia-SP (COELHO, 2006): escolaridade de nula até 8 anos; faixa etária de menos de 25, de 25 a 50 e de mais de 50 anos; e gêneros masculino e feminino; Chapecó-SC (TAMANINE, 2002): escolaridade primária, ginasial e secundária; faixa etária de até 45 anos e de mais de 50 anos; e gêneros masculino e feminino; Rio de Janeiro, Porto Alegre e Salvador-Projeto NURC (LOPES, 1999): escolaridade superior; faixa etária de 25 a 35, de 36 a 55 e de mais de 56 anos; e gêneros masculino e feminino. 
secundária; e a de Goiás-GO (46\% de emprego de nós), com informantes de escolaridade média e superior. Por outro lado, há discrepância entre variedades geograficamente próximas, como a de Florianópolis-SC (28\% de emprego de nós) e de Chapecó-SC (52\% de uso do nós), mesmo ambas contando com informantes de perfis sociais muito semelhantes.

Os resultados de outros trabalhos também demonstram que a variação diatópica não é relevante para a AP de 1PP, pois há variedades geograficamente distantes, como a de João Pessoa-PB, a de Pelotas-RS e a do interior paulista, com comportamentos semelhantes em relação ao uso de nós e a gente (79\%, 78\% e 73,8\% de emprego do pronome a gente, respectivamente).

\section{Variação na concordância verbal de primeira pessoa do plural (1PP)}

Após a observação e análise do fenômeno da AP de 1PP, passamos a tratar de dois outros fenômenos relacionados à 1PP: a CV variável junto do pronome nós e do pronome a gente. A seguir, apresentamos os resultados gerais para esses dois fenômenos.

\section{Tabela 2 - Concordância verbal de primeira pessoa do plural no português brasileiro do interior paulista.}

\begin{tabular}{ccccc}
\hline & PRONOME & \multicolumn{2}{c}{ NÓS } & \multicolumn{2}{c}{ A GENTE } \\
\cline { 2 - 5 } & & 3PS & 1PP & 3PS \\
\hline $\begin{array}{c}\text { VARIEDADE } \\
\text { paulista }\end{array}$ & $85,5 \%(488 / 570)$ & $14,5 \%(82 / 570)$ & $6 \%(98 / 1603)$ & $94 \%(1505 / 1603)$ \\
\hline
\end{tabular}

Fonte: RUBIO (2012).

No PB do interior paulista, evidencia-se, junto do pronome nós, uma frequência de uso de 85,5\% de formas em 1PP (como em (4.b)) e de 14,5\%, de formas em 3PS (como em (4.b)). Já a regra de CV com a genteé praticamente semicategórica, em favor de formas verbais em 3PS (como em (4.c)), com percentual de 94\%, contra apenas 6\% de emprego de 1PP (como em (4.d)).

(4.a) Nós nunca desconfiô(u) de nada... porque viVIA dentro da sua casa... a gente conviVIA ali

[BDI-090-500] 
(4.b) aí nós tivemo(s) a oportunidade de..... conhecê(r) Fernando de Noronha...

[BDI-051-215]

(4.c) mais um po(u)co pra frente... já tem uma entradazinha... né? que a gente fala que é a Lagoa Seca né?

[BDI-132-195]

(4.d) meu irmão/ a gente dividimo(s) o lo:.te... meu irmão tá construindo no fun::.do uma casa

[BDI -038-170]

Considerando as diferentes características dos fenômenos variáveis aqui considerados, apresentamos, no quadro que se segue, a ordem de seleção das variáveis neles atuantes.

\section{Quadro 5 - Ordem de seleção das variáveis consideradas para os fenômenos de concordância verbal de primeira pessoa do plural no português brasileiro do interior paulista.}

\begin{tabular}{|c|c|c|c|}
\hline \multicolumn{2}{|c|}{$\begin{array}{ll}\text { Variáveis } & \text { Fenômeno }\end{array}$} & $\begin{array}{c}\text { CV com nós } \\
\text { PB do interior paulista }\end{array}$ & $\begin{array}{c}\text { CV com a gente } \\
\text { PB do interior paulista }\end{array}$ \\
\hline \multirow{5}{*}{ 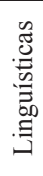 } & Explicitude do sujeito & $5^{\circ}$ & $4^{\circ}$ \\
\hline & Paralelismo discursivo & $4^{\circ}$ & $1^{\circ}$ \\
\hline & Saliência fônica verbal & $2^{\circ}$ & $2^{\circ}$ \\
\hline & Tempo e modo verbal & não selecionada & não selecionada \\
\hline & Grau de determinação do sujeito & não selecionada & $3^{\circ}$ \\
\hline \multirow{3}{*}{ 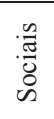 } & Gênero & não selecionada & não selecionada \\
\hline & Faixa etária & $3^{\circ}$ & $5^{\circ}$ \\
\hline & Escolaridade & $1^{\circ}$ & não selecionada \\
\hline
\end{tabular}

Fonte: RUBIO (2012).

A seleção das variáveis exibida acima justifica a consideração dos casos de possíveis variações em relação à CV de 1PP de forma individual, uma vez que cada um dos fenômenos variáveis apresenta diferente ordem de seleção dos fatores e diferentes fatores relevantes no processo de variação. Para a CV com nós, por exemplo, destaca-se a relevância de dois, dos três fatores sociais considerados, inclusive com a seleção de escolaridade como variável mais relevante. Da observação das variáveis consideradas para a CV com a gente, entretanto, verificase menor influência de variáveis sociais, já que apenas faixa etária foi selecionada e, diga-se, como última na ordem de relevância, e maior influência de variáveis estruturais, com a seleção de quatro, das cinco consideradas. 
Nos dois próximos gráficos, efetuamos a comparação dos resultados obtidos em nosso estudo para a CV de 1PP com nós e a gente com os resultados de outras variedades do $\mathrm{PB}$.

\section{Gráfico 2 - Concordância verbal com o pronome nós em variedades do português brasileiro.}

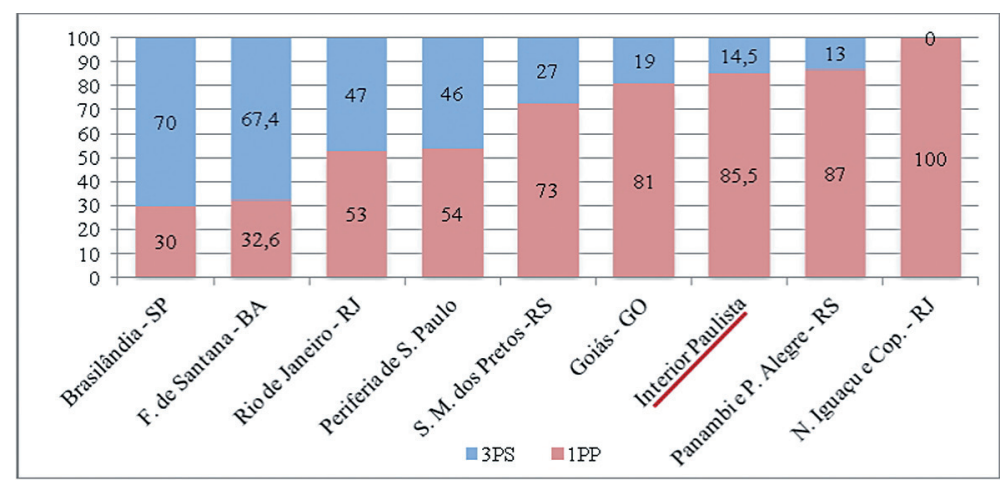

Fonte: Elaboração própria. ${ }^{17}$

Em relação à forma de 1PP concordante com o pronome nós, com base nos dados do gráfico 2, verifica-se que o fenômeno se atesta como variável para a maioria das variedades pesquisadas, em maior ou menor grau de emprego das formas verbais de 1PP, com variação de até 57 pontos percentuais (variedade de Brasilândia vs. variedade de Panambi e de Porto Alegre). Se consideradas as variedades do PB de Copacabana e Nova Iguaçu, no Rio de Janeiro, contudo, constata-se emprego categórico de formas verbais de 1PP junto do pronome nós.

A frequência de emprego da desinência de 1PP com o pronome nós apresentada nas amostras de fala do interior paulista (85,5\%), a princípio, surpreende, por ser mais elevada que a apresentada em inúmeras outras variedades. Entretanto, a

17 Características sociais das amostras: Brasilândia-Periferia de SP (COELHO, 2006): escolaridade de nula até 8 anos, faixa etária de menos de 25, de 25 a 50 e de mais de 50 anos e gêneros masculino e feminino; Feira de Santana-BA (CARMO; ARAÚJO, 2010): escolaridades nula e fundamental (português popular), faixas etárias diversas, informadas no trabalho, e gêneros masculino e feminino; Rio de Janeiro-RJ (NARO; GORSKI; FERNANDES, 1999): escolaridade de até 3 anos e de 4 a 8 anos, faixa etária de 6 a 12, 13 a 20, 21 a 40 e mais de 40 anos e gêneros masculino e feminino; Periferia de São Paulo (RODRIGUES, 1987): escolaridade nula e de até 4 anos, faixa etária de 20 a 35, 36 a 50 e mais de 51 anos e gêneros feminino e masculino; São Miguel dos PretosRS (ALMEIDA, 2006): escolaridade não explicitada, faixa etária de 15 a 24, 40 a 64 e 65 a 90 anos e gêneros masculino e feminino; Goiás-GO (MATTOS, 2010): escolaridade ensino médio e superior, faixa etária de menos de 21, de 21 a 40 e acima de 41 anos e gêneros masculino e feminino; Interior Paulista-Iboruna (RUBIO, 2012): escolaridade fundamental, média, superior, faixa etária de 16 a 25, 26 a 35, 36 a 55 e mais de 55 anos e gêneros feminino e masculino; Panambi e Porto Alegre-RS (ZILLES; MAYA; SILVA, 2000): escolaridade de baixa até superior, faixa etária de 25 a 49 e mais de 50 anos e gêneros feminino e masculino; Nova Iguaçu e Copacabana -RJ (VIANNA, 2011): escolaridade fundamental, média e superior, faixa etária de 18 a 35, de 36 a 55 e mais de 55 anos e gêneros masculino e feminino. 
observação das características sociais de cada corpus, principalmente o nível de escolaridade dos informantes, fornece explicações para a frequência mais elevada da amostra do interior de São Paulo: as amostras que apresentam menores frequências de verbos em 1PP com o pronome nós possuem, quase em sua totalidade (exceção feita para a amostra de Goiás, que possui frequência inferior de CV (81\%), mas bastante próxima da frequência de CV do interior paulista $(85,5 \%))$, informantes com níveis de escolaridade menores do que os da amostra do banco de dados Iboruna e também das amostras de CV de Panambi e Porto Alegre e de Nova Iguaçu e Copacabana, as quais apresentam todos os informantes com escolaridade superior.

A consideração apenas das frequências gerais de emprego das formas de 1PP e de 3PS junto do pronome nós e das características sociais dos informantes, obviamente, não permite que se determine com clareza todos os fatores responsáveis pela amplitude de variação na CV entre as diversas variedades do PB, porém é possível confirmar, de antemão, que, diferentemente do fenômeno variável de AP nós e a gente, o fenômeno variável de CV de 1PP com nós é influenciado diretamente pelo nível de escolarização.

Vejamos, agora, o gráfico 3, comparativo da CV com o pronome a gente.

\section{Gráfico 3 - Concordância verbal com a forma pronominal a gente em variedades do português brasileiro.}

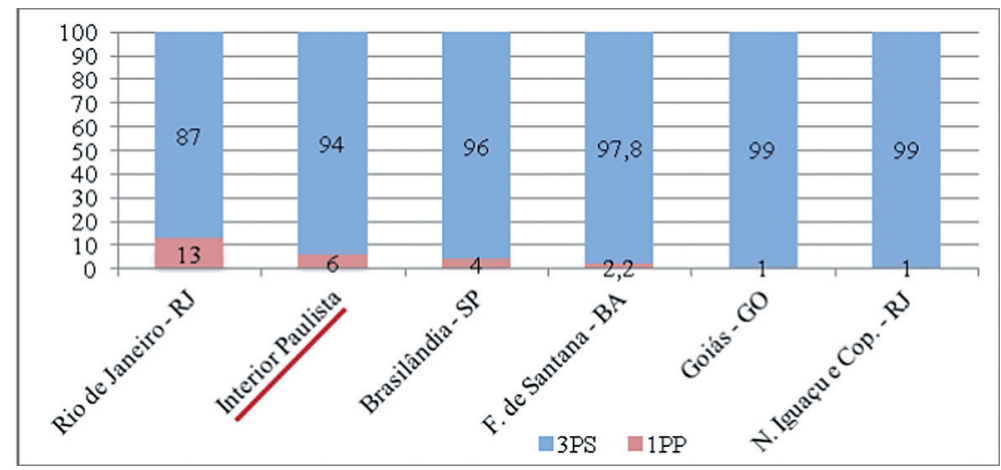

Fonte: Elaboração própria. ${ }^{18}$

18 Características sociais das amostras: Rio de Janeiro-RJ (NARO; GORSKI; FERNANDES, 1999): escolaridade de até 3 anos e de 4 a 8 anos, faixa etária de 6 a 12, 13 a 20, 21 a 40 e mais de 40 anos e gêneros masculino e feminino; Interior Paulista- Iboruna (RUBIO, 2012): escolaridade fundamental, média, superior, faixa etária de 16 a 25, 26 a 35, 36 a 55 e mais de 55 anos e gêneros feminino e masculino; Brasilândia-Periferia de São Paulo (COELHO, 2006): escolaridade: de nula até 8 anos, faixa etária de menos de 25, de 25 a 50 e de mais de 50 anos e gêneros masculino e feminino; Feira de Santana-BA (CARMO; ARAÚJO, 2010): escolaridade nula e fundamental (português popular), faixas etárias diversas, não informadas e gêneros masculino e feminino; Goiás-GO (MATTOS, 2010): escolaridade média e superior, faixa etária de menos de 21, de 21 a 40 e acima de 41 anos e gêneros masculino e feminino; Nova Iguaçu e Copacabana-RJ (VIANNA, 2011): escolaridade 
A CV com pronome a gente não pode ser caracterizada como fenômeno amplamente variável no $\mathrm{PB}$, pois, na maioria das variedades consideradas, o emprego de formas verbais de 3PS supera 95\% (Brasilândia-periferia de São Paulo, Feira de Santana-BA, municípios do estado de Goiás, Nova Iguaçu e CopacabanaRJ), sugerindo aplicação semicategórica dessas formas junto do pronome. A amostra do interior paulista apresentou uma variação pouco superior a 5\%, o que faz com que o fenômeno de CV junto de a gente na comunidade também se classifique como semicategórico, com grande predominância de formas verbais de 3PS junto do pronome a gente. Das variedades investigadas, a única para a qual o fenômeno pode ser considerado variável é a do Rio de Janeiro-RJ, que apresentou 13\% de uso de 1PP para a forma a gente.

\section{Variação na concordância verbal de terceira pessoa do plural (3PP)}

São inúmeros os estudos sociolinguísticos que tratam da CV de 3PP nas variedades do PB e muitas são as variáveis linguísticas e sociais que demonstram exercer influência sobre o fenômeno nessas variedades. Apresentamos, a seguir, os resultados relativos à CV de 3PP, para a fala do interior paulista.

\section{Tabela 3 - Concordância verbal de terceira pessoa do plural no português brasileiro do interior paulista}

\begin{tabular}{cccc}
\hline VARIEDADE & $\begin{array}{c}\text { DESINÊNCIA DE } \\
\text { 3PP }\end{array}$ & $\begin{array}{c}\text { DESINÊNCIA DE } \\
\text { 3PS }\end{array}$ & TOTAL \\
\hline $\begin{array}{c}\text { PB - interior } \\
\text { paulista }\end{array}$ & $73 \%(1.971)$ & $27 \%(728)$ & $100 \%(2.699)$ \\
\hline
\end{tabular}

Fonte: RUBIO (2012).

Os resultados gerais apontam uma frequência de $73 \%$ de emprego de formas em 3PP junto de sujeitos de 3PP (ocorrência (5.a)), e de 27\% em 3PS com sujeitos em 3PP (ocorrência (5.b)). As variáveis relevantes para os fenômenos seguem apresentadas no quadro 6 , a seguir.

(5.a) até os noivos foram hospitalizados... na Santa Casa de Rio Preto... não puderam nem seguir para a lua-de-mel... ficaram ali hospitalizados

[BDI-113-85]

fundamental, média e superior, faixa etária de 18 a 35, de 36 a 55 e mais de 55 anos e gêneros masculino e feminino. 
(5.b) nessa fazenda... meus avôs fez um cercado... fez um pomar de:: jabuticaba... então... quando as jabuticabas nasciam... que estavam na época de colher eles...ela tocava né... um... beRRANte...

[BDI-102-174]

\begin{abstract}
Quadro 6 - Ordem de seleção das variáveis para o fenômeno de concordância verbal de terceira pessoa do plural no português brasileiro do interior paulista.
\end{abstract}

\begin{tabular}{|c|c|c|}
\hline \multicolumn{2}{|r|}{ Fenômeno } & CV DE 3PP no PB do interior paulista \\
\hline \multirow{6}{*}{ 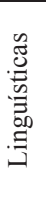 } & Posição do sujeito & $6^{\circ}$ \\
\hline & Traço semântico do referente do sujeito & $5^{\circ}$ \\
\hline & Paralelismo formal discursivo & $2^{\circ}$ \\
\hline & Saliência fônica verbal & $3^{\circ}$ \\
\hline & Paralelismo formal oracional & $4^{\circ}$ \\
\hline & Tipo morfológico do sujeito & não selecionada \\
\hline \multirow{3}{*}{ 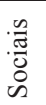 } & Escolaridade & $1^{\circ}$ \\
\hline & Faixa etária & $7^{\circ}$ \\
\hline & Gênero & $8^{\circ}$ \\
\hline
\end{tabular}

Fonte: RUBIO (2012).

De acordo com os resultados do quadro 6, observa-se que a CV de 3PP na fala do interior paulista sofre a influência direta de variáveis de natureza tanto linguística quanto social, o que se confirma pela seleção de oito delas, das nove consideradas, com destaque para a variável social escolaridade, primeira em ordem de relevância, e para as variáveis linguísticas paralelismo linguístico discursivo e saliência fônica, selecionadas em $2^{\circ}$ e $3^{\circ}$ lugares, respectivamente. Variáveis relacionadas ao sujeito não se mostraram de grande relevância, já que duas delas foram selecionadas em quinto e sexto lugares (traço semântico e posição, respectivamente) e a terceira não foi selecionada (tipo morfológico). Acrescente-se ainda que a seleção da variável escolaridade como a mais relevante aponta que o fenômeno é fortemente estigmatizado na fala do interior paulista, a exemplo do que ocorre no PB, em geral. No gráfico 4, apresentamos a comparação dos resultados gerais obtidos em nosso estudo com os de outras variedades do PB. 


\section{Gráfico 4 - Concordância verbal de terceira pessoa do plural em diferentes variedades do português brasileiro.}

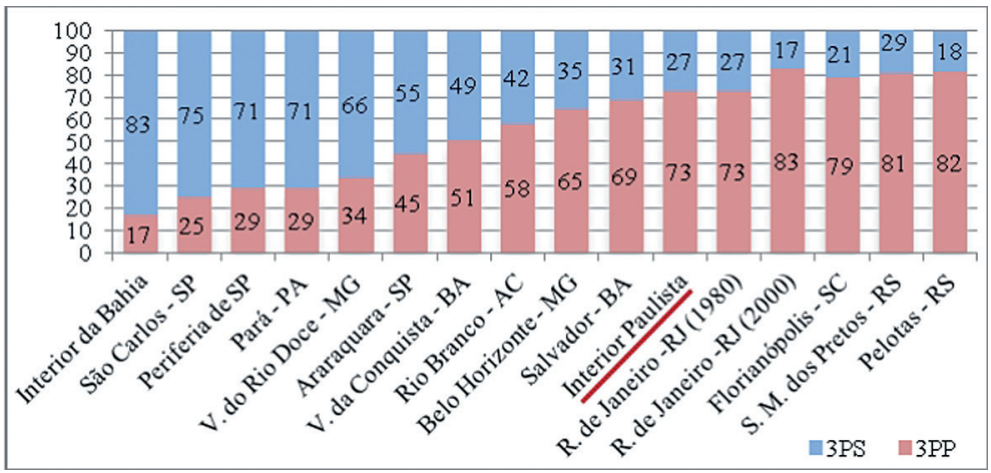

Fonte: Elaboração própria. ${ }^{19}$

Como se pode observar, a CV de 3PP atinge diferentes frequências nas variedades do PB, o que se comprova, inclusive, pela observação dos extremos do gráfico, que revelam discrepância de 65 pontos percentuais entre a amostra do interior da Bahia (17\% de verbos em 3PP) e a amostra de Pelotas-RS (82\% de CV de 3PP). Da mesma forma, a diferença de frequências entre variedades de regiões próximas, como a da região Noroeste de SP (73\% de CV de 3PP) e a da região Central do estado de SP (45\% de CV de 3PP), pode chegar a 28 pontos percentuais, e entre cidades vizinhas do interior de SP, como a de Araraquara (45\% de uso de 3PP) e de São Carlos (25\% de 3PP), a 20 pontos percentuais.

19 Características sociais das amostras: Interior da Bahia-Português popular (SILVA, 2005): escolaridade nula ou fundamental; faixa etária variável, de 25 a 107 anos; e gêneros masculino e feminino; São Carlos-SP (MONTE, 2007): analfabetos e escolarizados (EJA); faixa etária variável, de 22 a 38 anos; e gêneros masculino e feminino; Periferia de São Paulo (RODRIGUES, 1987): escolaridade nula e de até quatro anos; faixa etária de 20 a 35, de 36 a 50 e de mais de 51 anos; e gêneros masculino e feminino; Pará-PA (NINA, 1980): escolaridade nula (somente analfabetos); faixa etária variável, de 25 a 75 anos; e gêneros feminino e masculino; Vale do Rio Doce-MG (GONÇALVES, 2007): escolaridade fundamental, média e superior; faixa etária de 15 a 18, de 35 a 45 e de mais de 63 anos; e gêneros masculino e feminino; Araraquara-SP (GAMEIRO, 2005): escolaridade variável, de nula até mais de 12 anos, faixa etária de 7 a 15, de 16 a 25, de 26 a 55 e de mais de 55 anos; e gêneros masculino e feminino; Vitória da Conquista-BA (OLIVEIRA, 2005): escolaridade fundamental, média e superior; faixa etária de 15 a 25, de 26 a 49 e de mais de 50 anos; e gêneros masculino e feminino; Rio Branco-AC (RODRIGUES, 1997): analfabetos, 1 a 4 anos e 5 a 8 anos de escolaridade; faixa etária de 20 a 35 anos; e gêneros masculino e feminino; Belo Horizonte-MG (FARIA, 2008): escolaridade fundamental, média e superior; faixa etária de 17 a 29 anos; e gêneros masculino e feminino; Salvador-BA (SOUZA, 2011): escolaridade fundamental, média e superior, faixa etária de 15 a 24, de 25 a 35, de 45 a 55 e de mais de 65 anos; e gêneros masculino e feminino; Rio de Janeiro-RJ (SCHERRE; NARO, 2010): escolaridade de 1 a 4 anos, de 5 a 9 anos e de 9 a 11 anos; faixa etária de 7 a 14, de 15 a 25, de 26 a 49 e de mais de 49 anos; e gêneros masculino e feminino; Interior PaulistaIboruna (RUBIO, 2012): escolaridade de 1 a 4, de 5 a 8, de 9 a 11 e de mais de 12 anos; faixa etária de 16 a 25, de 26 a 35, de 36 a 55 e de mais de 55 anos; e gêneros masculino e feminino; Florianópolis-SC (MONGUILHOTT; COELHO, 2002): escolaridade de 4 anos e 11 anos, faixa etária de 15 a 25, de 26 a 49 e de mais de 49 anos; e gêneros masculino e feminino; São Miguel do Pretos-RS (ALMEIDA, 2006): escolaridade não explicitada; faixa etária de 16 a 24, de 40 a 64 e de 65 a 90 anos; e gêneros masculino e feminino; Pelotas-RS (WELCHEN, 2009): escolaridade fundamental, média, superior e pós-graduação; faixa etária de 15 a 25, de 26 a 49 e de mais de 49 anos; e gêneros masculino e feminino. 
Os resultados alcançados para cada variedade dependem, obviamente, dos fatores sociais considerados na composição das amostras de fala das comunidades investigadas, principalmente o fator escolaridade. As variedades que apresentaram menores frequências de pluralização verbal são também as que possuem informantes com os menores níveis de escolaridade (amostra do interior da Bahia, de São Carlos-SP, da periferia da cidade de São Paulo e do Pará). Por outro lado, as amostras que apresentaram maiores frequências de emprego da variante padrão, verbos em 3PP, possuem informantes com escolarização superior.

Se compararmos as frequências para a variedade carioca de 1980, reapresentadas em Scherre e Naro (2010), e as da variedade do interior paulista, é possível notar os mesmos percentuais de CV de 3PP, 73\%, ainda que haja distância cronológica, geográfica e social entre as amostras. O mesmo se pode observar também nas pesquisas da periferia de São Paulo e na amostra do Pará, que exibiram, ambas, 29\% de emprego de verbos em 3PP para sujeitos de 3PP.

\section{Conclusões}

Na exposição dos resultados gerais para os fenômenos variáveis relacionados à CV e à AP no PB do interior paulista, procuramos situá-los no cenário mais amplo da sociolinguística brasileira, mostrando aproximações e distanciamentos desta variedade em relação a outras do PB, sem deixar de nos atentarmos para as características consideradas na estratificação social das comunidades de fala comparadas. Propomos, abaixo, um quadro que sumariza os resultados alcançados para os fenômenos investigados na fala do interior paulista e as respectivas variáveis linguísticas e sociais atuantes em cada um deles.

\section{Quadro 7 - Características dos fenômenos variáveis relacionados à concordância verbal e à alternância pronominal no português brasileiro do interior paulista.}

\begin{tabular}{|c|c|}
\hline \multirow[b]{2}{*}{ FENÔMENOS } & $\begin{array}{l}\text { PORTUGUÊS BRASILEIRO DO INTERIOR PAULISTA } \\
\text { BANCO DE DADOS IBORUNA }\end{array}$ \\
\hline & COMPORTAMENTO / VARIÁVEIS ATUANTES \\
\hline \multirow{2}{*}{$\begin{array}{c}\text { ALTERNÂNCIA } \\
\text { PRONOMINAL } \\
\text { DE } 1^{\mathrm{a}} \text { PESSOA DO PLURAL }\end{array}$} & variável \\
\hline & $\begin{array}{l}\text { paralelismo discursivo }>\text { saliência fônica }>\text { grau de determinação do } \\
\text { sujeito }>\text { tempo e modo verbal }>\text { escolaridade }>\text { faixa etária. }\end{array}$ \\
\hline \multirow{2}{*}{$\begin{array}{l}\text { CONCORDÂNCIA VERBAL } \\
\text { COM NÓS }\end{array}$} & variável \\
\hline & $\begin{array}{l}\text { saliência fônica > paralelismo discursivo }>\text { explicitude do sujeito }> \\
\text { escolaridade }>\text { faixa etária. }\end{array}$ \\
\hline \multirow{2}{*}{$\begin{array}{l}\text { CONCORDÂNCIA VERBAL } \\
\text { COM } A \text { GENTE }\end{array}$} & semicategórica \\
\hline & $\begin{array}{l}\text { paralelismo discursivo }>\text { saliência fônica }>\text { grau de determinação do } \\
\text { sujeito }>\text { explicitude do sujeito }>\text { faixa etária. }\end{array}$ \\
\hline \multirow{2}{*}{$\begin{array}{c}\text { CONCORDÂNCIA VERBAL } \\
\text { DE } 3^{\mathrm{a}} \text { PESSOA } \\
\text { DO PLURAL }\end{array}$} & variável \\
\hline & $\begin{array}{l}\text { paralelismo discursivo }>\text { saliência fônica }>\text { paralelismo oracional }> \\
\text { traço semântico do sujeito }>\text { posição do sujeito }>\text { escolaridade }> \\
\text { faixa etária }>\text { gênero. }\end{array}$ \\
\hline
\end{tabular}

Fonte: RUBIO (2012). 
Ainda que, por questão de limitação de espaço, não tenhamos discutido em pormenores os resultados para cada uma das variáveis atuantes nos diferentes fenômenos variáveis, a visão panorâmica que oferecemos permitiu constatar que, na fala do interior paulista, observadas as mesmas características sociais de outras comunidades de fala do PB: (i) prevalece, com acentuada frequência, o uso de a gente em detrimento de nós, com influência apenas da variável faixa etária, como na maior parte das variedades do PB; (ii) a concordância verbal com nós em 1PP apresenta índices bastante elevados, como a de outras variedades do sul e sudeste do Brasil; (iii) a concordância verbal com a gente constitui regra semicategórica, como se observa também na maior parte do dialetos do PB; (iv) a concordância verbal de 3PP apresenta índices acima dos 70\%, como ocorre em outras variedades do sul e sudeste do país.

Continuam, no interior do Projeto ALIP, os trabalhos de descrição da fala do interior paulista, a partir dos quais esperamos, na próxima década, seja possível revelar, por completo, uma fotografia sociolinguística da região.

RUBIO, C. F.; GONÇALVES, S. C. L. The Speech from the Countryside Region of São Paulo State in the Brazilian Sociolinguistics Panorama: an Overview of Verbal Agreement and Pronominal Alternation. Alfa, São Paulo, v.56, n.3, p.993-1024, 2012.

- ABSTRACT: As part of sociolinguistic researches developed by ALIP (speech samples from the countryside region of São Paulo) Project, in this paper we present general results for three variable phenomena of speech from countryside region of São Paulo State: (i) verbal agreement of first person plural; (ii) verbal agreement of third person plural; (iii) pronominal alternation between the forms of first person plural of discourse "nós" (we) and "a gente". Based on principles of Labovian Sociolinguistics, whereby interdialectal comparison, we show how these variable phenomena are inserted in the Brazilian Sociolinguistics panorama. The results allow us to find similarities and differences among the speech from countryside region of São Paulo State and other varieties from Brazilian Portuguese, highlighting the relevance of the description of this variety still little known in the Brazilian Sociolinguistics panorama.

- KEYWORDS: Paulista Portuguese. Verbal agreement. Pronominal alternation.

\section{REFERÊNCIAS}

ALMEIDA, A. P. A concordância verbal na comunidade de São Miguel dos Pretos, Restinga Seca, RS. 2006. 159 f. Dissertação (Mestrado em Letras) - Universidade Federal do Rio Grande do Sul, Porto Alegre, 2006.

AMARAL, A. O dialeto caipira. 3.ed. São Paulo: Hucitec, 1976.

AMARAL, L. I. C. A concordância verbal de segunda pessoa do singular em Pelotas e suas implicações linguísticas e sociais. 2003. 181 f. Dissertação (Mestrado em Letras) - Universidade Federal do Rio Grande do Sul, Porto Alegre, 2003. 
ANTONINO, V.; BANDEIRA, M. Nós, a gente e a concordância em uma comunidade afro-brasileira isolada. Papia, São Paulo, n.21, v.1, p.159-176, 2011.

BECHARA, E. Moderna gramática portuguesa. 37.ed. Rio de Janeiro: Lucerna, 2002.

BENTES, A. C. É nóis na fita: sobre a formação de registros e a elaboração de estilos no campo da cultura popular urbana paulista. 2009. Projeto de Pesquisa financiado pela FAPESP, Universidade Estadual de Campinas, Campinas, 2009.

BORGES, P. R. S. A gramaticalização de "a gente" no português brasileiro. 2004. 182 f. Tese (Doutorado em Letras) - Universidade Federal do Rio Grande do Sul, Porto Alegre, 2004.

BORTONI-RICARDO, S. M. The urbanization of rural dialect speakers: a sociolinguistic study in Brazil. Cambridge: University Press, 1985.

CARENO, M. F. Vale do Ribeira: a voz a vez das comunidades negras. São Paulo: Arte \& Ciência, 1997.

CARMO, M. C. As vogais médias pretônicas dos verbos na fala culta do interior paulista. 2009. 122 f. Dissertação (Mestrado em Estudos Linguísticos) Universidade Estadual Paulista, São José do Rio Preto, 2009.

CARMO, S. D. S.; ARAÚJO, S. S. F. A concordância verbal com a primeira pessoa do plural no português popular falado em feira de Santana-BA. In: SEMINÁRIO DE INICIAÇÃO CIENTÍFICA DA UNIVERSIDADE ESTADUAL DE FEIRA DE SANTANA, 14., 2010, Santana. Anais... Santana: UEFS, 2010. p.575-580.

CASTILHO,A. T. (Org.). História do português paulista. Campinas: Ed. da Unicamp, 2009. (Série Estudos).

. Português culto falado no Brasil: história do Projeto NURC/BR. In: PRETI, D., URBANO, H. (Org.). A linguagem falada culta na cidade de São Paulo. São Paulo: T. A. Queiroz, 1990. (Estudos; v.4).

COELHO, R. É nóis na fita! Duas variáveis linguísticas numa vizinhança da periferia paulistana. 2006. 175 f. Dissertação (Mestrado em Linguística) - Universidade de São Paulo, São Paulo, 2006.

CUNHA, C.; CINTRA, L. Gramática do Português contemporâneo. Rio de Janeiro: Nova Fronteira, 1984.

DUARTE, M. E. L. Variação e sintaxe: clítico acusativo, pronome lexical e categoria vazia no português do Brasil. 1986. 150f. Dissertação (Mestrado em Linguística) - Pontifícia Universidade Católica, São Paulo, 1986. 
FARIA, N. V. M. A concordância verbal no português de Belo Horizonte. 2008. 142f. Dissertação (Mestrado em Língua Portuguesa e Linguística) - Pontifícia Universidade Católica de Minas Gerais, Belo Horizonte, 2008.

FELÍCIO, C. P. Gramaticalização da conjunção concessiva 'embora'. 2008. $140 \mathrm{f}$. Dissertação (Mestrado em Estudos Linguísticos) - Universidade Estadual Paulista, São José do Rio Preto, 2008.

FERNANDES, E. A. Nós x a gente: variação estável ou mudança em progresso? In: SOARES, M. E.; ARAGÃO, M. S. S. (Ed.). In: JORNADA DE ESTUDOS LINGUÍSTICOS, 16., 1999, Fortaleza. Anais... Fortaleza: UFC, 1999. p.331-334.

FERNANDES, F. O. Construções com os verbos andar, continuar, ficar e viver seguidos de gerúndio: um estudo na interface sociolinguística/gramaticalização. 2010. 110f. Trabalho de Iniciação Científica (Licenciatura em Letras) - Universidade Estadual Paulista, São José do Rio Preto, São Paulo, 2010.

FERREIRA, J. S. O apagamento do /d/ em morfema de gerúndio no dialeto de São José do Rio Preto. 2010. 145f. Dissertação (Mestrado em Estudos Linguísticos) Universidade Estadual Paulista, São José do Rio Preto.

FIAMENGUI, A. H. R. A marcação de pluralidade no SN na fala e na escrita de adolescentes da região de São José do Rio Preto. 2011. 144f. Dissertação (Mestrado em Estudos Linguísticos) - Universidade Estadual Paulista, São José do Rio Preto, 2011.

FONSECA,A. M. H. A perífrase verbal ir + infinitivo e o futuro do dialeto riopretano: um estudo na interface sociolinguística/gramaticalização. 2010. 176f. Dissertação (Mestrado em Estudos Linguísticos) - Universidade Estadual Paulista, São José do Rio Preto, 2010.

FORTILLI, S. C. Orações completivas em posição argumental de sujeito: gramaticalização e dessentencialização de orações matrizes. 2011. 98f. Tese (Doutorado em Estudos Linguísticos) - Universidade Estadual Paulista, São José do Rio Preto, 2011.

As construções não-verbais no português falado no interior do Estado de São Paulo. 2007. 145f. Dissertação (Mestrado em Estudos Linguísticos) Universidade Estadual Paulista, São José do Rio Preto, 2007.

GAMEIRO, M. B. A concordância verbal na língua falada da região central do estado de São Paulo. 2005. 198f. Dissertação (Mestrado em Língua Portuguesa) - Universidade Estadual Paulista, Araraquara, 2005.

GONÇALVES, S. C. L. Orações completivas em posição argumental de sujeito II: sincronia e diacronia. 2012. Projeto de Pesquisa financiado pelo CNPq, Universidade Estadual Paulista, São José do Rio Preto, 2012. 
. Orações subjetivas: variância e invariância de padrões na fala e na escrita. Revista da ABRALIN, Brasília, v.10, p.87-111, 2011.

. Projeto ALIP (amostra linguística do interior paulista): questões teóricas e metodológicas sobre a constituição de um banco de dados de língua falada. In: TAGNIN, E.; VALE, O. A. (Org.). Avanços da lingüística de corpus no Brasil. São Paulo: Humanitas, 2008. p.217-245.

O português falado na região de São José do Rio Preto: constituição de um banco de dados anotado para o seu estudo. Relatório científico parcial I apresentado à FAPESP, Universidade Estadual Paulista, São José do Rio Preto, 2005. Disponível em <http://www.iboruna.ibilce.unesp.br/histórico/relatorio1>. Acesso em: 22 fev. 2011.

GRACIOSA, D. M. D. Concordância verbal na fala culta carioca. 1991. $176 f$. Dissertação (Mestrado em Linguística) - Universidade Federal do Rio de Janeiro, Rio de Janeiro, 1991.

GUERRA, A. R. Funções textual-interativas dos marcadores discursivos. 2007. 233f. Dissertação (Mestrado em Estudos Linguísticos) - Universidade Estadual Paulista, São José do Rio Preto, 2007.

HAUSEN, T. A. P. Concordância verbal do pronome tu no interior do estado de Santa Catarina. 2000. 143f. Dissertação (Mestrado em Letras) - Universidade Federal do Paraná, Curitiba, 2000.

INSTITUTO BRASILEIRO DE GEOGRAFIA E ESTATÍSTICA [IBGE]. CenSO demográfico 2000. Brasília, 2000. Disponível em: <http://www.ibge.gov.br/home/ estatistica/populacao/default_censo_2000.shtm>. Acesso em: 20 out. 2002.

LABOV, W. Sociolinguistic patterns. Philadelfia: University of Pensylvania Press, 1972.

LEMLE, M.; NARO, A. J. Competências básicas do Português. Rio de Janeiro: Mobral/Fundação Ford, 1977.

LIMA, A. C. Predicações não-verbais avaliativas encaixadas em predicados avaliativos. 2012. 20f. Projeto de Pesquisa para o Mestrado, Universidade Estadual Paulista, São José do Rio Preto, 2012.

LOPES, C. R. S. A inserção de a gente no quadro pronominal do português: percurso histórico. 1999. 181f. Tese (Doutorado em Língua Portuguesa) - Universidade Federal do Rio de Janeiro, Rio de Janeiro, 1999.

LOPES, Q.; NARO, A. J. Concordância variável de primeira pessoa do singular no PB - amostra variável. In: CONGRESSO NACIONAL DE LINGUÍSTICA E FILOLOGIA, DO CÍRCULO DE ESTUDOS LINGUÍSTICOS E FILOLÓGICOS DO RIO 
DE JANEIRO, 15., Rio de Janeiro. Anais... Rio de Janeiro: UERJ, 2011. Disponível em: <http://www.filologia.org.br>. Acesso em: 23 out. 2011.

LOREGIAN, L. Concordância verbal com o pronome tu na fala do sul do Brasil. 1996. 156f. Dissertação (Mestrado em Linguística) - Universidade Federal de Santa Catarina, Florianópolis, 1996.

LUCCHESI, D.; BAXTER, A.; SILVA, J. A. A. A concordância verbal. In: LUCCHESI, D.; BAXTER, A.; RIBEIRO, I. (Org.). O português afro-brasileiro. Salvador: Ed. da UFBA, 2009. p.331-371.

MARCATO, F. Análise prosódica de clíticos preposicionais na variedade riopretense. 2011. 20f. Projeto de Dissertação (Mestrado em Estudos Linguísticos) - Universidade Estadual Paulista, São José do Rio Preto, 2011.

MATTOS, S. E. R. A primeira pessoa do plural em Goiás. In: MARÇALO, M. J. et al. (Ed.). Língua portuguesa: ultrapassar fronteiras, juntar culturas. Évora: Universidade de Évora, 2010. p.11-22.

. Sujeito coletivo singular em português: concordância e referencialidade. 2003. 105f. Dissertação (Mestrado em Linguística) - Universidade Federal de Brasília, Brasília, 2003.

MENDES, R. B. SP2010: construção de uma amostra da fala paulistana. 2011. Projeto de pesquisa financiado pela FAPESP, Universidade de São Paulo, São Paulo, 2011.

MODESTO, A. T. T. Formas de tratamento no português brasileiro: a alternância tu/você na cidade de Santos-SP. 2006. 128f. Dissertação (Mestrado em Linguística) - Universidade de São Paulo, São Paulo, 2006.

MONGUILHOTT, I. O. S.; COELHO, I. L. Um estudo da concordância verbal de terceira pessoa em Florianópolis. In:VANDRESEN, P. (Org.). Variação e mudança no português falado na região sul. Pelotas: Educat, 2002. p.189-216.

MONTE, A. Concordância verbal e variação: uma fotografia sociolinguística da cidade de São Carlos. 2007. 114 f. Dissertação (Mestrado) - Universidade Estadual Paulista, Araraquara, 2007.

NARO, A. J.; GÖRSKI, E.; FERNANDES, E. Change without change. Language variation and change, Cambridge, v.11, n.2, p.197-211, 1999.

NARO, A. J.; SCHERRE, M. M. P. Sobre o efeito do princípio da saliência na concordância verbal na fala moderna, na escrita antiga e na escrita moderna. In: MOURA, D. (org.) Os múltiplos usos da língua. Maceió: EDUFAL, 1999. p.26-37.

A hierarquização do controle da concordância no português moderno e medieval: o caso de estruturas de sujeito composto. In: GROBE, S.; ZIMMERMANN, 
K. (Org.). O português brasileiro: pesquisas e projetos. Frankfurt am Main: TFM, 2000a. p.167-188.

. Variable concord in Portuguese: the situation in Brazil and Portugal. In: MCWHORTHER, J. (Org.). Language change and language contact in pidgins and creoles. Amsterdam: John Benjamins, 2000b. p.235-255.

A relação verbo/sujeito: o efeito máscara do que relativo. In: HORA, D.; COLLISCHONN, G. Teoria linguística: fonologia e outros temas. João Pessoa: Universitária, 2003. p.383-401.

. Origens do português brasileiro. São Paulo: Parábola Editorial, 2007.

NEVES, M. H. M. Gramática de usos do português. São Paulo: Ed. da UNESP, 2000.

NICOLAU, E. M. D. A ausência de concordância verbal em português: uma abordagem sociolinguística. 1984. 179f. Dissertação (Mestrado em Linguística e Língua Portuguesa) - Universidade Federal de Minas Gerais, Belo Horizonte, 1984.

NINA, T. J. C. Concordância nominal/verbal do analfabeto na microrregião de Bragantina. 1980. 130f. Dissertação (Mestrado em Língua Portuguesa) - Pontifícia Universidade Católica do Rio Grande do Sul, Porto Alegre, 1980.

OLIVEIRA, M. S. Concordância verbal de terceira pessoa do plural em Vitória da Conquista: um caso de variação estável. 2005. 177f. Dissertação (Mestrado em Letras) - Universidade Federal da Bahia, Salvador, 2005.

OMENA, N. P. A referência à primeira pessoa do plural: variação ou mudança? In: PAIVA, M. de C.; DUARTE, M. E. L. (Org.). Mudança linguística em tempo real. Rio de Janeiro: Contra Capa Livraria, 2003.

. A referência variável da primeira pessoa do discurso no Plural. In: NARO,A. J. et al. Relatório final de pesquisa: projeto subsídios do projeto censo à educação. Rio de Janeiro: Ed. da UFRJ, 1986. p.286-319.

OMENA, N. P.; BRAGA, M. L. A gente está se gramaticalizando? In: MACEDO, A. T.; RONCARATI, C.; MOLLICA, M. C. (Org.). Variação e discurso. Rio de Janeiro: Tempo Brasileiro, 1996. p.75-84.

ORLANDI, P. S. Usos e (des)usos da flexão verbal de $2^{a}$ pessoa do singular em texto orais de informantes de Tubarão (SC): um estudo de caso. 2004. 86f. Dissertação (Mestrado em Ciências da Linguagem) - Universidade do Sul de Santa Catarina, Tubarão, 2004.

PENHAVEL, E. Marcadores discursivos e articulação tópica. 2010. 136f. Tese (Doutorado em Linguística) - Universidade Estadual de Campinas, Campinas, 2010. 
PAREDES SILVA, V. L. A variação você/tu na fala carioca. In: ENCONTRO DE VARIAÇÃO LINGUÍSTICA DO CONE SUL, 1, 1996, Porto Alegre. Anais... Porto Alegre: UFRGS, 1996. Não paginado.

PERINI, M. A. Gramática do português brasileiro. São Paulo: Parábola, 2010.

RAMOS, A. P. Descrição das vogais postônicas não-finais na variedade do noroeste paulista. 2009. 177f. Dissertação (Mestrado em Estudos Linguísticos) Universidade Estadual Paulista.

RENCK, N. R. Renovação e gramaticalização: o caso da locução conjuntiva. 2011. 54f. Trabalho de Iniciação Científica (Licenciatura em Letras) - Universidade Estadual Paulista, São José do Rio Preto, 2011.

RODRIGUES, A. C. S. A concordância verbal no português popular em São Paulo. 1987. 189f. Tese (Doutorado em Língua Portuguesa) - Universidade de São Paulo, São Paulo, 1987.

RODRIGUES,A. N. O dialeto caipira na região de Piracicaba. São Paulo: Ática, 1974.

RODRIGUES, D. A. A concordância verbal na fala urbana de Rio Branco. 1997. 198f. Dissertação (Mestrado em Linguística) - Universidade Estadual de Campinas, Campinas, 1997.

RONCARATI, C. Banco de dados interacionais. Rio de Janeiro: Universidade Federal do Rio Janeiro, 1996.

RUBIO, C. F. Padrões de concordância verbal e de alternância pronominal no português brasileiro e europeu: estudo sociolinguístico comparativo. 2012. $392 \mathrm{f}$. Tese (Doutorado em Estudos Linguísticos) - Universidade Estadual Paulista, São José do Rio Preto, 2012.

A concordância verbal na região noroeste do Estado de São Paulo. 2008. 152f. Dissertação (Mestrado em Estudos Linguísticos) - Universidade Estadual Paulista, São José do Rio Preto, 2008.

SALOMÃO, M. H. A variação de pluralidade nas estruturas predicativas da variedade falada na região de São José do Rio Preto. 2010. 162f. Dissertação (Mestrado em Estudos Linguísticos). Universidade Estadual Paulista, São José do Rio Preto, 2010.

SANTANA, L. Relações de complementação no português brasileiro: uma perspectiva discursivo-funcional. São Paulo: Cultura Acadêmica, 2010.

SANTOS, R. M. A. A alternância indicativo/subjuntivo em estruturas complexas. 2005. 152f. Dissertação (Mestrado em Estudos Linguísticos) - Universidade Estadual Paulista, São José do Rio Preto, 2005. 
SCHERRE, M. M. P.; NARO,A. J. Perceptual vs. grammatical constraints and social factors in subject-verb agreement in Brazilian Portuguese. U. Penn Working Papers in Linguistics, Honolulu, v.16, n.2, p.165-171, 2010.

. Mudança sem mudança: a concordância de número no português brasileiro. Scripta, Belo Horizonte, v. 1, n. 18, 2006. p. 162-185.

. Sobre as origens estruturais do português brasileiro: crioulização ou mudança natural? Papia - Revista de crioulos de base Ibérica, Brasília: Thesaurus, 2001.

. Sobre a concordância de número no português falado do Brasil. In: RUFFINO, G. (Org.). Dialettologia, geolinguistica, sociolinguística. Tubingen: Max NiemayerVerlag, 1998a. p.153-188.

Restrições sintáticas e semânticas no controle da concordância verbal em português. Fórum linguístico, Florianópolis, n. 1, p. 45-71, 1998b.

. A concordância de número no português do Brasil: um caso típico de variação inerente. In: HORA, D. (org.) Diversidade linguística no Brasil. João Pessoa: Ideia, 1997. p.93-114.

Duas dimensões do paralelismo formal na concordância de número no português popular do Brasil. DELTA, São Paulo, v.9, n.1, p.1-14, 1993.

SEARA, I. C. A variação do sujeito nós e a gente na fala florianopolitana. Organon, Porto Alegre, v.14, n.28-29, p.179-194, 2000.

SILVA, J. A. A. A concordância verbal de terceira pessoa do plural no português popular do Brasil: um panorama sociolinguístico de três comunidades do interior da Bahia. 2005. 340f. Tese (Doutorado em Letras) - Universidade Federal da Bahia, Salvador, 2005.

SILVA, G. M. O. Variáveis sociais e perfil do corpus CENSO. In: SILVA, G. M. O.; SCHERRE, M. M. P. (Org.). Padrões sociolinguísticos. Rio de Janeiro: Tempo Brasileiro, 1996. p.51-81.

SILVA, G. M. O.; SCHERRE, M. M. P. Padrões sociolinguísticos: análise de fenômenos variáveis do português falado na cidade do Rio de Janeiro. Rio de Janeiro: Tempo Brasileiro, 1996.

SILVEIRA, A. A. M. As vogais pretônicas na fala culta do noroeste paulista. 2008. 143f. Dissertação (Mestrado em Estudos Linguísticos) - Universidade Estadual Paulista, São José do Rio Preto, 2008.

SOUZA, C. B. A concordância verbal no português falado em Salvador: uma realidade linguística bipolarizada. Papia, Brasília, n.21, v.2, p.183-193, 2011.

SOUZA, E. R. F. Gramaticalização dos itens linguísticos 'assim', 'já' e 'aí no português brasileiro: um estudo sob a perspectiva da gramática discursivo- 
funcional. 2009. 290f. Tese (Doutorado em Linguística) - Universidade Estadual de Campinas, Campinas, 2009.

TAMANINE, A. M. B. A alternância nós/a gente no interior de Santa Catarina. 2002. 120f. Dissertação (Mestrado em Letras) - Universidade Federal do Paraná, Curitiba, 2002.

VENDRAME, V. Os verbos ver, ouvir e sentir e a expressão de evidencialidade em língua portuguesa. 2010. 140f. Tese (Doutorado em Estudos Linguísticos) Universidade Estadual Paulista, São José do Rio Preto, 2010.

VIANNA, J. B. S. Semelhanças e diferenças na implementação de a gente em variedades do português. 2011. 235f. Tese (Doutorado em Letras Vernáculas) Universidade Federal do Rio de Janeiro, Rio de Janeiro, 2011.

A concordância de nós e a gente em estruturas predicativas na fala e na escrita carioca. 2006. 109f. Dissertação (Mestrado em Língua Portuguesa) Universidade Federal do Rio de Janeiro, Rio de Janeiro, 2006.

VOTRE, S.; OLIVEIRA, M. R. A língua falada e escrita na cidade do Rio de Janeiro: materiais para seu estudo. Rio de Janeiro: UFRJ, 1995.

WEINREICH, U.; LABOV, W.; HERZOG, M. Empirical foundations for a theory of language change. In: LHEMAN, W.; MALKIEL, Y. (Ed.). Directions for historical linguistics. Austin: University of Texas Press, 1968. p.95-195.

WIEDEMER, M. L. Variação e gramaticalização de preposições de complementos locativos de verbos de movimento. 2011. 88f. Relatório Científico, Universidade Estadual Paulista, São José do Rio Preto.

ZILLES, A. M. S. O que a fala e a escrita nos dizem sobre a avaliação social do uso de a gente? Letras de Hoje, Porto Alegre, v.42, n.2, p.27-44, 2007.

. The development of a new pronoun: the linguistic and social embedding of a gente in Brazilian Portuguese. Language Variation and Change, Cambridge, v.17, n.1, p.19-53, 2005.

ZILLES, A. M. S.; MAYA, L.; SILVA, K. A concordância verbal com a primeira pessoa do plural em Panambi e Porto Alegre, RS. Organon, Porto Alegre, v.14, n.28/29, p.195-219, 2000.

Recebido em março de 2012

Aprovado em maio de 2012 